\title{
COMUNICAÇÃO DA CIÊNCIA: DIVERSAS CONCEPÇÕES DE UMA MESMA COMPLEXIDADE
}

\author{
SCIENCE COMMUNICATION: SOME CONCEPTIONS OF THE SAME \\ COMPLEXITY
}

\section{COMUNICACIÓN DE LA CIENCIA: VARIADAS CONCEPCIONES DE UNA MISMA COMPLEJIDAD}

\section{Resumo}

Maria Ataide Malcher Doutora, Universidade Federal do Pará ataidemalcher@uol.com.br

Luciana Miranda Costa Doutora, Universidade Federal do Pará lmirandaeua@gmail.com

Suzana Cunha Lopes Mestranda, Universidade Federal do Pará suzanaclopes@yahoo.com.br

Neste artigo, apresentamos parte de uma pesquisa empírica sobre os processos comunicacionais desenvolvidos em uma experiência amazônica, em que buscamos refletir sobre as concepções teóricas e as práticas que envolvem a relação entre a ciência e os diferentes públicos. No diálogo com autores da Comunicação e de áreas afins, trazemos as falas de crianças, adolescentes e adultos que integram o Clube do Pesquisador Mirim, uma ação de iniciação científica desenvolvida, desde 1997, pelo Museu Paraense Emílio Goeldi (MPEG), com sede em Belém, no Pará. Percebemos nas noções de divulgação científica e suas variantes que se sobressai uma visão difusionista, por isso defendemos a necessidade de discutir, de forma mais abrangente, na área da Comunicação, o processo de comunicação da ciência.

Palavras-chave: Comunicação. Comunicação da ciência. Divulgação científica. 


\begin{abstract}
In this article, we present a part of an empirical research about the communicational processes developed in a Amazon experience, in which we reflect on the theoretical conceptions and practices involving the relationship between science and different audiences. In dialogue with the authors of the Communication and related areas, we bring the discourses of children, adolescents and adults who are participants of the Clube do Pesquisador Mirim, a scientific initiation action developed, since 1997, by Museu Paraense Emílio Goeldi (MPEG), in Belém, Pará. We perceive in notions of scientific communication and its variants that they have a diffusionist vision, so we defend the need to discuss, more broadly, in the area of Communication, the process of science communication.
\end{abstract}

Keywords: Communication. Science communication. Scientific communication.

\title{
Resumen
}

En este artículo, presentamos parte de una investigación empírica sobre los procesos comunicacionales desarrollados en una experiencia amazónica, en el cual buscamos reflexionar sobre las concepciones teóricas y las prácticas que involucran la relación entre la ciencia e los diferentes públicos. En el diálogo con autores de la Comunicación y de áreas próximas, traemos los discursos de niños, jóvenes y adultos que integran el Clube do Pesquisador Mirim, una acción de iniciación científica desarrollada, desde 1997, por el Museu Paraense Emílio Goeldi (MPEG), con sede en Belém, en Pará. Percibimos en las nociones de divulgación científica y sus variaciones que se sobresale una visión difusionista, por eso defendemos la necesidad de discutir, de manera más ampliada, en el área de la Comunicación, el proceso de comunicación de la ciencia.

Palabras-clave: Comunicación. Comunicación de la ciência. Divulgación científica.

\section{INTRODUÇÃO}

Teoricamente, o termo divulgação científica remete a uma ação difusionista, caracterizada pela separação espacial e cultural dos agentes participantes. Nesse sentido, configura uma disseminação linear da ciência, o que, de fato, é o que se verifica em muitas iniciativas dessa natureza.

A partir, porém, de uma pesquisa empírica sobre os processos comunicacionais desenvolvidos em uma experiência amazônica, buscamos refletir e repensar as concepções teóricas e as práticas que envolvem a relação entre a ciência e os diferentes públicos. No diálogo com autores da Comunicação e de áreas afins, traremos as falas e as observações de crianças, adolescentes e adultos que integram o Clube do Pesquisador Mirim ${ }^{1}$, uma ação de

\footnotetext{
1 No site do Museu Goeldi, existe uma página sobre o Clube do Pesquisador Mirim. O conteúdo está desatualizado, mas é possível encontrar algumas informações sobre o desenvolvimento desta ação: http://www.museu-goeldi.br/eva/educacao/cpm/cpm.html.
} 
iniciação científica desenvolvida, desde 1997, pelo Museu Paraense Emílio Goeldi (MPEG), com sede em Belém, no estado do Pará.

Tradicional instituição de pesquisa, o MPEG foi fundado em 1866. Em 1954, foi integrado ao Conselho Nacional de Pesquisa ${ }^{2}$ e em 2000 passou a estar diretamente vinculado ao então Ministério da Ciência e Tecnologia. Hoje é referência nacional e internacional nas áreas de Antropologia, Arqueologia, Botânica, Ciências da Terra, Linguística e Zoologia.

O Clube tem a proposta de oferecer, prioritariamente, aos estudantes do ensino fundamental, mas também contemplando estudantes do ensino médio, experiências de compartilhamento e produção de conhecimento científico, de maneira interativa e colaborativa. Apesar de institucionalmente ser considerado uma ação de iniciação ou educação científica, o Clube reúne algumas características interessantes de serem analisadas a partir da área da Comunicação, pois está centrado na iniciação e apropriação da ciência, que compreendemos, em termos teóricos, caracterizadas como processos comunicacionais, se adotarmos a perspectiva de Braga (2011) de que este é composto por interações sociais que se desenvolvem em tempos, espaços e contextos múltiplos, sejam mediadas tecnologicamente ou face a face.

Todos os anos, o Clube forma grupos de até 20 crianças e adolescentes, denominados pesquisadores mirins, conduzidos por instrutores, que são técnicos, bolsistas e estagiários do Serviço de Educação, com formações em diversas áreas. Os grupos são formados de acordo com a idade, série escolar e a temática a ser trabalhada durante um ano. Geralmente, os assuntos são baseados nas áreas de referência do MPEG: Botânica, Zoologia, Ciências Humanas e Ciências da Terra.

No início de cada ano, após o estabelecimento das temáticas pelos instrutores, é aberto um processo seletivo para o ingresso dos pesquisadores mirins. Aqueles que já participaram em outros anos também podem se candidatar novamente às vagas e são avaliados pela sua trajetória no Clube. Em 2012, 165 crianças e adolescentes inscreveram-se para ingressar no Clube, dos quais 135 foram aprovados e, no final do ano, 114 permaneceram oficialmente nas atividades.

A quantidade de grupos formados depende da demanda de vagas e da possibilidade de oferta de acordo com a infraestrutura e os instrutores disponíveis no Serviço de Educação. Quando é possível, são compostos grupos em outros municípios paraenses que desenvolvem as atividades em espaços cedidos por escolas ou universidades. Desde 2007, o Clube

\footnotetext{
${ }^{2}$ Hoje, Conselho Nacional de Desenvolvimento Científico e Tecnológico (CNPq).
} 
possibilita o ingresso de pesquisadores mirins com deficiência auditiva, que são acompanhados por intérpretes de Língua Brasileira de Sinais (LIBRAS) em grupos denominados inclusivos. Em 2012, foram formados sete grupos em Belém:

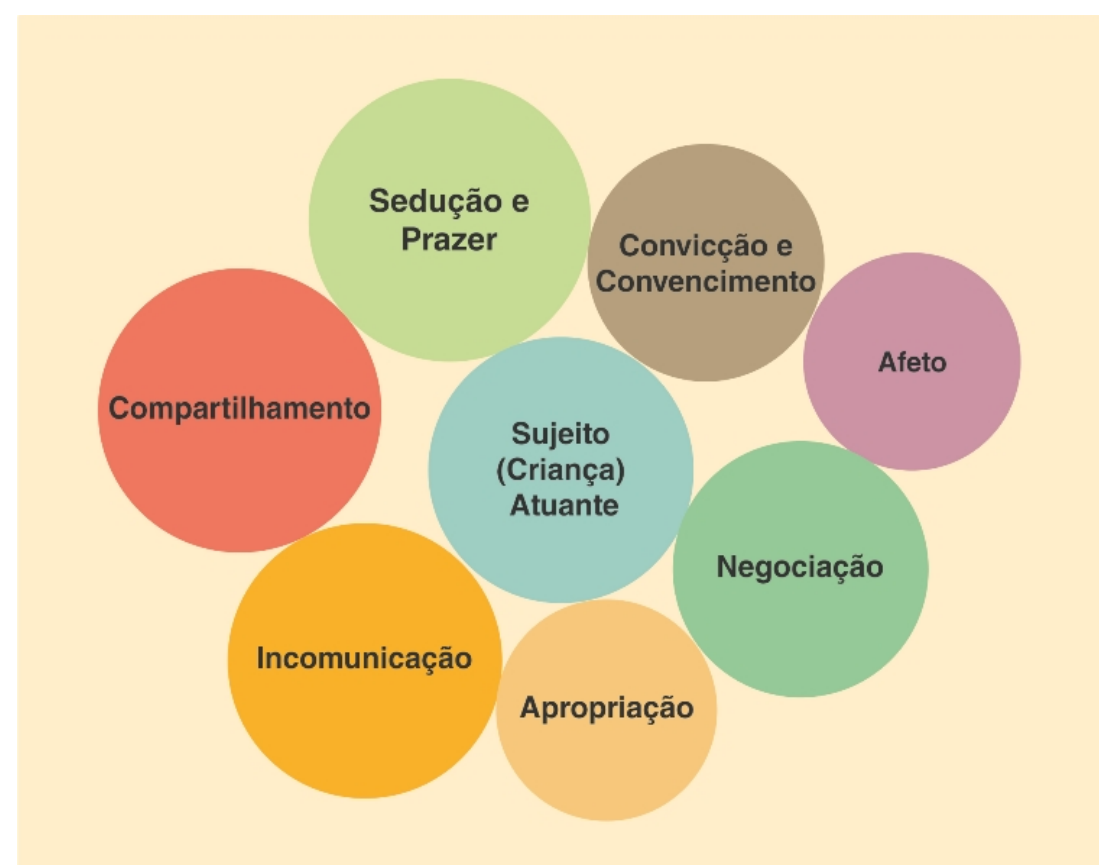

FIGURA 01 - Grupos temáticos do Clube do Pesquisador Mirim em 2012. * Grupo inclusivo, com 2 pesquisadores mirins surdos. Fonte: acervo da pesquisa.

Neste contexto, desenvolvemos uma pesquisa empírica de caráter exploratório, lançando mão de diferentes procedimentos metodológicos a partir de uma perspectiva transmetodológica (MALDONADO, 2008), que consiste em um desenho metodológico que articula diversificadas técnicas e métodos de forma coerente com a postura teórica do pesquisador de produzir conhecimento científico de forma inovadora.

Nossa pesquisa, assim, congregou observações não-participante e participante de atividades do Clube, realização de grupos focais com a participação de pesquisadores mirins e entrevistas semiestruturadas com instrutores e ex-pesquisadores mirins, além de outros procedimentos de campo ${ }^{3}$ cujos dados e análises serão apresentados em artigos futuros. A seguir, apresentamos os perfis dos grupos focais e dos entrevistados, a fim de identificar os autores das falas que traremos nas discussões deste artigo:

\footnotetext{
${ }^{3}$ Outros procedimentos realizados: questionário exploratório sobre o perfil dos pesquisadores mirins, autoobservação.
} 
GRUPO FOCAL 1 - Reunimos pesquisadores mirins do grupo Conhecendo o Museu Goeldi e que tinham o perfil em comum de serem todos novatos no Clube.

GRUPO FOCAL 2 - Reunimos os pesquisadores mirins do grupo Clube On Line, os chamados veteranos, com três anos ou mais de participação no Clube.

GRUPO FOCAL 3 - Montamos um grupo misto com um, dois ou três representantes de cada um dos outros cinco grupos do Clube.

FIGURA 02 - Perfil dos grupos focais. Fonte: acervo da pesquisa. 
INSTRUTORA 1 - 25 anos, bolsista PCl/CNPq do Setor de Educação do Museu, instrutora do Clube há 3 anos, possui graduação em Biologia, especialização em Metodologia em Ciências Naturais e cursa mestrado em Educação em Ciências.

INSTRUTORA 2 - 49 anos, bolsista do Projeto Conhecer para Preservar e responsável pelo Biblioteca Clara Galvão, ambos do Setor de Educação do Museu, instrutora do Clube há 15 anos, possui graduação em Biblioteconomia e especialização em Planejamento e Gestão do Desenvolvimento Regional.

INSTRUTORA 3 - 47 anos, técnica do Serviço de Educação do Museu, instrutora do Clube há 15 anos, possui graduação em Turismo e especialização em Educação Ambiental.

INSTRUTOR 4 - 49 anos, bolsista PCI/CNPq do Serviço de Educação do Museu, instrutor do Clube há 3 anos, possui graduação em Tecnólogo em Processamento de Dados e especializações em Redes e Desenvolvimento de Sistemas.

INSTRUTORA 5 - 22 anos, estagiária de ensino superior do Serviço de Educação do Museu, instrutora do Clube há 1 ano, cursa graduação em Biblioteconomia.

INSTRUTOR 6 - 33 anos, bolsista do Projeto Conhecer para Preservar, instrutor do Clube há 3 anos, possui graduação em Agronomia e especialização em Produção de Biodiesel.

INSTRUTOR 7 - 49 anos, técnico e coordenador do Serviço de Educação do Museu, instrutor do Clube há 15 anos, possui graduação em Biologia.

INSTRUTOR 8 - 44 anos, técnico do Serviço de Educação do Museu, instrutor do Clube há 15 anos, possui ensino médio completo.

FIGURA 03 - Perfil dos instrutores entrevistados. Fonte: acervo da pesquisa. 


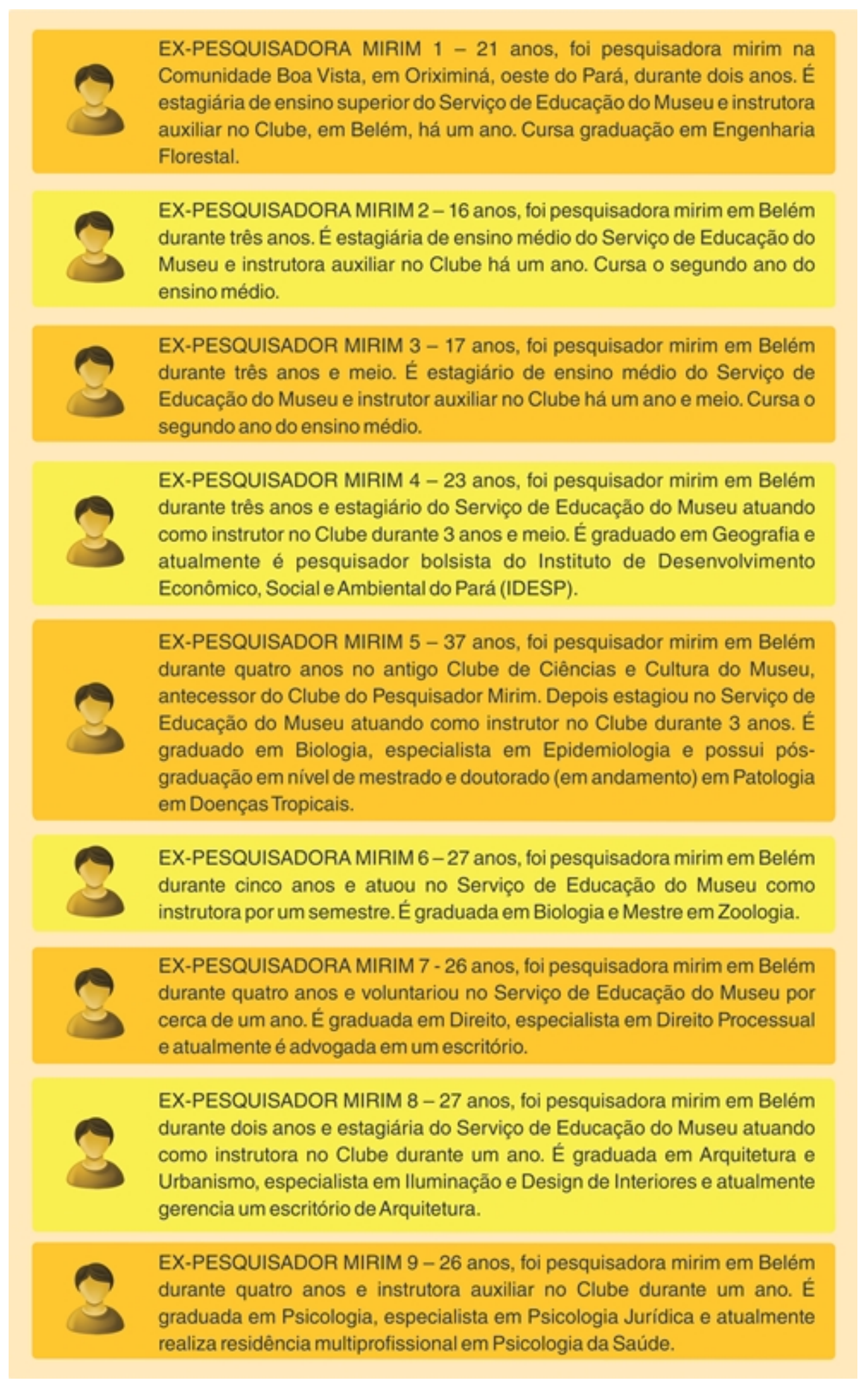

FIGURA 04 - Perfil dos ex-pesquisadores mirins entrevistados. Fonte: acervo da pesquisa. 


\title{
2 DIVULGAÇÃO CIENTÍFICA: DIVERSAS CONCEPÇÕES
}

Apresentamos ao leitor algumas concepções de divulgação científica, a partir de um diálogo permanente entre diversos autores e os agentes que participaram de nossa pesquisa empírica. Massarani e Moreira (2005) apresentam as três linhas mais comuns do que denominam de comunicação científica: a primeira seria formada por discursos científicos primários, produzidos por cientistas para outros cientistas; a segunda se refere a discursos científicos didáticos, que geralmente compõem manuais de ensino; e a terceira linha seria a dos discursos científicos divulgativos, da chamada divulgação científica propriamente dita, voltada a públicos não iniciados.

Sobre essa divulgação voltada aos pares, um ex-pesquisador mirim destaca sua importância para o desenvolvimento da ciência, mas ressalta que essa divulgação precisa ser abrangente a mais públicos:

\begin{abstract}
Existe aqui o lado que a gente publica em artigos científicos, várias, diversas revistas a gente publica aqui e isso fica restrito, porque a nossa moeda de troca, para quem é pesquisador, para quem quer conseguir verba, tu tens que ter artigo publicado e é bom isso. Não estou reclamando, não. Isso é bom, porque isso daí faz com haja esse fluxo contínuo de transmissão de dados e essa publicação de artigos seja mesmo contínua. Não pode parar isso, não pode mesmo. (...) O importante é passar para a comunidade científica, mas também para a comunidade local, mostrar o que está se fazendo. '-Bora passar tudo para a comunidade'. Isso eu aprendi no Museu Goeldi (EXPESQUISADOR MIRIM 5, 2013).
\end{abstract}

Zamboni (2001) fala em divulgação científica para se referir estritamente à relação estabelecida entre o cientista e o público em geral, termo para o qual elenca três recorrentes representações: a) como atividade de difusão do conhecimento; b) como partilha social do saber; e c) como atividade de reformulação discursiva. Em relação à atividade de difusão do conhecimento, Zamboni escreve:

A divulgação científica é entendida, de modo genérico, como uma atividade de difusão, dirigida para fora de seu contexto originário, de conhecimentos científicos produzidos e circulantes no interior de uma comunidade de limites restritos, mobilizando diferentes recursos, técnicas e processos para a veiculação das informações científicas e tecnológicas ao público em geral (ZAMBONI, 2001, p. 45-6, grifo nosso). 
Podemos claramente visualizar esse conceito de divulgação científica como atividade de difusão no modelo transmissivo de comunicação elaborado por Lasswell, em que a difusão de informações pressupõe a estrutura de um emissor, que envia uma mensagem, por um canal, a um receptor, causando determinado(s) efeito(s) (WOLF, 1995). Nesse sentido, o emissor (quem?) seria o divulgador científico (o próprio cientista ou o profissional da comunicação), a mensagem (o que?) seria o conteúdo da ciência a ser trabalhado em uma linguagem acessível e a ser transmitido pelos meios de comunicação (por que canal?) a um público leigo em geral ou direcionado (a quem?), quando se trata, por exemplo, de divulgação científica para crianças. Um possível efeito (com que efeito?) seria o aprendizado dos resultados das pesquisas científicas.

Essa visão transmissiva da divulgação científica é recorrente na fala de alguns agentes do Clube participantes de nossa pesquisa.

Acredito que seria repassar, dependendo do tipo de comunicação, aquilo que é produzido em meios científicos (INSTRUTORA 1, 2013).

É toda a responsabilidade de passar para as crianças determinada informação que o nosso tema sugere: Conhecendo o Museu. Então, o Museu é muito amplo, tem muita coisa para aprender. Então, a minha função é: eu sou um meio de comunicação da informação principal até as crianças (INSTRUTORA 5, 2013).

Transmitir alguma informação, através de pesquisa e de experiências. Acredito que seja isso, divulgação científica (EX-PESQUISADORA MIRIM 1, 2013).

É uma coisa que facilita a ciência a chegar às pessoas, à sociedade (EXPESQUISADOR MIRIM 3, 2013).

Eu acho que é repassar o que está se aprendendo, o que está sendo descoberto, repassar para sociedade o que está sendo feito e por que está sendo feito pra que quando aquele conhecimento for usado seja valorizado (EX-PESQUISADORA MIRIM 6, 2013).

É interessante notar que, apesar de demonstrarem, em outros momentos, ter concepções e desenvolver práticas para além desse modelo transmissivo, ao buscarem simplificar a explicação do que percebem como divulgação científica, os agentes do Clube recaem na noção de transferência de conhecimentos. Esta contradição está longe de ser pontual à experiência do Museu. Pelo contrário, é indicativa de uma problemática maior que tem a ver com a carência de outras formas de pensar a própria comunicação. 
Somos formados a partir de uma visão funcionalista da comunicação, o que torna ainda maior o desafio de buscar outras referências para compreender sua complexidade. Isso talvez explique por que, mesmo quando buscamos no âmbito teórico uma visão mais ampla da divulgação científica, acabamos remetendo ao modelo transmissivo de comunicação. Por exemplo, na segunda concepção de divulgação científica discutida por Zamboni (2001), a autora faz referência à partilha do saber científico, mas ainda como uma transposição de conhecimento de um campo, o científico, a outro, a sociedade em geral.

Já na terceira representação da divulgação científica como reformulação discursiva, o que se enfatiza é a importância da transposição de linguagens: da científica para a coloquial, de forma a possibilitar que uma informação científica de domínio do pesquisador seja legível, compreensível para um público leigo. É preciso, portanto, simplificar a linguagem original da ciência para que ela seja acessível para não iniciados no campo.

Também seguindo uma linha discursiva e tendo como público da divulgação a população em geral, Sánchez-Mora (2003) usa o termo divulgação da ciência como uma nova linguagem criada a partir da interpretação do conhecimento científico. A autora entende que, após especializar sua linguagem, a ciência tornou-se incompreensível para quem não é cientista. Divulgar, portanto, “é uma tarefa eminentemente inventiva que recria o conhecimento científico, para formar e ampliar a cultura científica do público” (SÁNCHEZMORA, 2003, p. 37).

Encontramos também no Clube essa percepção linguística da divulgação da ciência, quando alguns participantes de nossa pesquisa referem-se à importância do trabalho de transformação da linguagem científica para algo que seja mais acessível ao cotidiano das pessoas.

O ideal e a missão do Museu é gerar, produzir e divulgar conhecimento, comunicar o conhecimento que é gerado. Na verdade, eles [os setores de Pesquisa e de Educação] devem caminhar juntos, o ideal é isso. Aqui não é o que acontece. Eu não quero te dizer que os pesquisadores do Museu não publicam, não compartilham o conhecimento, eles compartilham. Só que a forma como eles compartilham não chega ao grande público. Não estou dizendo todos, mas alguns acham que publicar o artigo, indexar em uma revista, fazer um livro, divulgar entre os pares em um congresso, em um seminário, em um workshop, isso eles estão compartilhando com os pares deles, com os especialistas da área. Para o grande público é necessário você olhar para essa outra caixa [o Setor de Educação]. E essa outra caixa, a função dela é decodificar este teu conhecimento, é transformar essa tua linguagem científica. Não é banalizar, mas é você transformar a linguagem para que o público leigo possa ter o mesmo conhecimento, em um nível, lógico, dentro daquilo que é o nível dele. Não que ele seja inferior, mas que 
ele tenha entendimento de que isso aqui que foi gerado e produzido pela instituição, o leigo também tem e deve conhecer. De que forma? Uma exposição, uma cartilha, um vídeo (INSTRUTORA 3, 2013).

Apesar de reconhecerem a importância da adaptação da linguagem no processo de aproximação do conteúdo científico a diferentes públicos, alguns agentes do Clube paralelamente vislumbram que esse trabalho não se restringe a uma simples tradução, mas a um processo criativo de elaboração de estratégias para tornar determinados conteúdos mais atrativos. Um ex-pesquisador mirim que hoje atua como instrutor auxiliar, destaca, por exemplo, a proposta dos produtos que cada grupo elabora ao final de cada período sobre o tema trabalhado durante o ano.

Quando a gente produz o produto final, se fosse para compartilhar, era só pegar os que já têm, que há, tem muitos que não são conhecidos, e fazer uma releitura, o que já aconteceu, mas, claro, com melhorias, mas aí, também, ou então só pegar e aí: “-Ah, bora usar isso daqui, bora mostrar.” Porque aqui você está produzindo uma coisa nova e aí você vai expandir aquilo que você... Aquele conhecimento todo que você aprendeu, você depois vai estar naquele local, aí ele vai ajudar a, digamos, na parte de divulgação, vai mostrar novas opções, que tem vários... Tanto é que tem vários kits, vários jogos, várias cartilhas, para cada ano tem uma inovação diferente (EXPESQUISADOR MIRIM 3, 2013).

Para uma instrutora, as tecnologias educativas desenvolvidas pelo Clube não são apenas produtos, mas uma experimentação constante que gera conhecimentos a partir da vivência: “O conhecimento é gerado a cada prática educativa que é vivenciada aqui, seja ela uma oficina para professor, uma oficina para criança, um grupo do Clube, uma gincana, uma monitoria” (INSTRUTORA 3, 2013). Essa ideia de inventividade da divulgação, para nós, abre margem para que pensemos nessa atividade não apenas do ponto de vista prático ou técnico, mas também intelectual e, portanto, passível de reflexão e teorização, o que nossa pesquisa no Clube nos possibilitou vislumbrar e que nos parece mais interessante de discutir na área da Comunicação.

Capozoli (2002) e Alvim (2003) também nos dão asas para essa compreensão, trabalhando, respectivamente, com os termos divulgação científica e comunicação da ciência, ambos abrangendo tanto um público exterior ao campo científico como os próprios cientistas. O primeiro afirma que a "divulgação científica não é outra coisa senão um esforço de inteligibilidade do mundo que se busca e, ao mesmo tempo, se compartilha com os demais” 
(CAPOZOLI, 2002, p. 121) e o segundo acredita na "comunicação da ciência, como instrumento de alavancagem e disseminação da geração do conhecimento científico” (ALVIM, 2003, p. 50).

O que nos chama a atenção nessas noções é a visão de que a divulgação científica ou comunicação da ciência integram o processo de produção de conhecimento científico, por um lado, permitindo que o mundo seja analisado e esta análise seja partilhada e, por outro, incentivando a geração e a difusão de novos conhecimentos. Nesse sentido, para além de uma atividade acessória, a divulgação é essencial à ciência e contribui para o seu desenvolvimento.

Uma das instrutoras do Clube demonstra reconhecer essa importância e relata como, no Museu Goeldi, alguns pesquisadores já têm essa percepção:

\footnotetext{
Quando eles [pesquisadores do Museu] conseguem financiamento para os projetos deles, tem que estar pensada a divulgação, tem que estar pensada a comunicação. E alguns já fazem isso e fazem muito bem. Tanto que o pessoal da área de Arqueologia é muito sensível a isso, quando eles fazem um projeto de pesquisa, a área de comunicação já está contemplada desde o início. Monta exposições, materiais educativos. O pessoal da área de Humanas, na verdade, eles têm essa sensibilidade mais aflorada, mais na prática. Os outros um pouco menos (INSTRUTORA 3, 2013).
}

É interessante notar na fala de ex-pesquisadores mirins que seguiram carreira acadêmica uma maior percepção da importância da divulgação integrada ao fazer científico. Uma das entrevistadas, que atua nas áreas biológicas, demonstra uma visão e uma prática diferenciada de divulgação científica, não apenas restrita aos pares, mas abrangente à comunidade em geral, assim como possível em comunicações face a face com diferentes públicos.

Atualmente a minha divulgação é mais em forma de congressos, desses encontros que tem da área. A gente divulga, fica aquele registro ali impresso, mas eu também estou sempre falando, sempre comentando o que eu estou descobrindo, falando para as pessoas que não entendem e me perguntam a importância daquilo (EX-PESQUISADORA MIRIM 6, 2013).

\subsection{Variantes e derivantes da divulgação científica}

Um dos conceitos mais estudados e praticados no âmbito da divulgação científica no Brasil é o jornalismo científico. A principal referência brasileira é Bueno, que publicou na década de 1980 a primeira tese de doutoramento sobre esse tema, na qual escreve: 
O conceito de Jornalismo Científico deve, obrigatoriamente, incluir o de Jornalismo, apropriando-se das características enunciadas por Otto Groth: atualidade, universalidade, periodicidade, difusão. Na prática, isto significa dizer que ele se define: pela atualidade, ocupando-se de fatos (eventos, descobertas) ou pessoas (cientistas, tecnólogos, pesquisadores) que estejam direta ou indiretamente relacionados com o momento presente; pela universalidade, abrigando os diferentes ramos do conhecimento científico; pela periodicidade, mantendo o ritmo das publicações ou matérias, certamente antes em conformidade com o desenvolvimento peculiar da ciência do que com o próprio ritmo de edição dos veículos jornalísticos (oportunidade, segundo Groth); e pela difusão, o que pressupõe a sua circulação pela coletividade (BUENO, 1984, p. 21-22).

O conceito de jornalismo científico traz a especificidade da atividade jornalística, tanto do ponto de vista linguístico quanto em termos de abordagem do conteúdo e agrega uma função educativa:

O Jornalismo Científico deve estar atento para o fato, já lembrado por José Reis, de que, em muitos casos, ele se constitui na única fonte popular de informações sobre ciência e tecnologia. Num País como o nosso, caracterizado pelo ensino precário e desatualizado de Ciências, passa a ser a única forma pela qual os cidadãos tomam contato com a atividade e os produtos de tecnólogos e cientistas. Daí, a responsabilidade do profissional que exerce a função de informar, formar e conscientizar o público sobre questões e repercussões da ciência e tecnologia (BUENO, 1984, p. 33-4).

Também nessa perspectiva de cidadania é bastante utilizado o termo alfabetização científica (expressão traduzida da língua inglesa: scientific literacy). Vinculada à educação, a expressão possui acepções diferentes, tendo em comum a ideia de que o conhecimento sobre a ciência e sua dinâmica são basilares para a vida de qualquer pessoa. Durant (1994) cita as três noções mais comuns quando se usa o termo scientific literacy. Primeiro, a concepção de que a população precisa ter conhecimento mínimo das principais informações científicas. Segundo, a de que a sociedade precisa conhecer como a ciência é constituída e como o conhecimento científico é construído, ou seja, ter clareza das ações e métodos próprios da ciência.

A terceira acepção, que nos parece a principal contribuição de Durant (1994) para a discussão, é a ideia de que a ciência tem que ser conhecida não apenas a partir de seus conteúdos e métodos, mas, sobretudo, a partir de suas contradições internas, suas reais condições de produção, seus jogos de poder, seus embates teóricos, suas motivações individuais e sua existência coletiva. 
Chassot (2003), por sua vez, para além do conhecimento teórico do conteúdo científico, refere-se à alfabetização científica agregada a uma dimensão empírica transformadora, em que os "alfabetizados cientificamente não apenas tivessem facilitada a leitura do mundo em que vivem, mas entendessem as necessidades de transformá-lo - e preferencialmente, transformá-lo em algo melhor”.

Chassot é declarado como referência de uma das instrutoras do Clube, em cuja fala é possível perceber esse papel transformador quando ela faz a diferenciação entre divulgação e comunicação da ciência:

Para mim, a divulgação não tem a pretensão de transformação. No meu preconceito, no meu conceito, ela não tem essa ambição de transformar. Na minha cabeça, acho que posso estar falando besteira. Mas a comunicação tem esse poder e essa vontade de transformação. E eu acho que isso acontece dentro do Clube, tanto na vivência dos alunos, quanto no momento em que eles apresentam, publicam, tornam público o conhecimento que eles aprenderam. Que é uma outra forma, que de repente para vocês pode ser só divulgação. Mas dependendo de como você dinamiza, de como você trata a linguagem, ela pode ser também transformadora (INSTRUTORA 3, 2013).

Continuando nossa trajetória de exploração conceitual, outro termo frequentemente utilizado é popularização ou vulgarização da ciência referindo-se às atividades de disseminação da ciência para além do campo científico, incluindo o papel dos meios de comunicação massivos, as variadas formas de educação informal (com destaque para os museus, centros de ciência e outros ambientes similares) e, em menor grau a educação formal.

O autor chinês Jianmin (2005-2006) aponta cinco características fundamentais desse conceito e fenômeno. O primeiro é a estima que a popularização da ciência tem ganhado como estratégia política. No Brasil, temos no Ministério da Ciência, Tecnologia e Inovação um Departamento de Popularização e Difusão da Ciência e Tecnologia, que foi criado em 2003 e integra a Secretaria de Ciência e Tecnologia para Inclusão Social do Ministério. Na última década, é possível reconhecer várias estratégias empreendidas nesse sentido, como o apoio à ampliação e criação de centros e museus de ciências, a realização de olimpíadas nacionais ${ }^{4}$, envolvendo estudantes da educação básica, a criação de editais que contemplassem pesquisa científica e tecnológica na área de divulgação científica, a criação da Semana Nacional de Ciência e Tecnologia, entre outros investimentos públicos em popularização da ciência.

\footnotetext{
4 A Olimpíada Brasileira de Matemática das Escolas Públicas (OBEMEP), por exemplo, promovida pelo Instituto Nacional de Matemática Pura e Aplicada (Impa/MCTI), alcançou, em 2013, o número de mais de 47 mil inscritos, com representantes de 99,35\% dos municípios brasileiros (Fonte: www.mcti.gov.br).
} 
Jianmin (2005-2006) também aponta como aspecto da popularização da ciência o entretenimento e o lazer, tanto no que se refere à inclusão de museus e centros de ciências em roteiros turísticos quanto à crescente indústria dos games que faz sucesso, principalmente, entre os mais jovens. Nesse aspecto, o ambiente do Parque Zoobotânico do Museu Goeldi, por exemplo, caracteriza-se por proporcionar essa maior aproximação com o público, tanto o turista quanto, principalmente, os próprios habitantes da cidade.

No âmbito do Clube, o Parque constitui-se como ambiente de pesquisa onde se realizam várias atividades em que os pesquisadores mirins se sentem à vontade e livres para construir coletivamente vários conhecimentos.

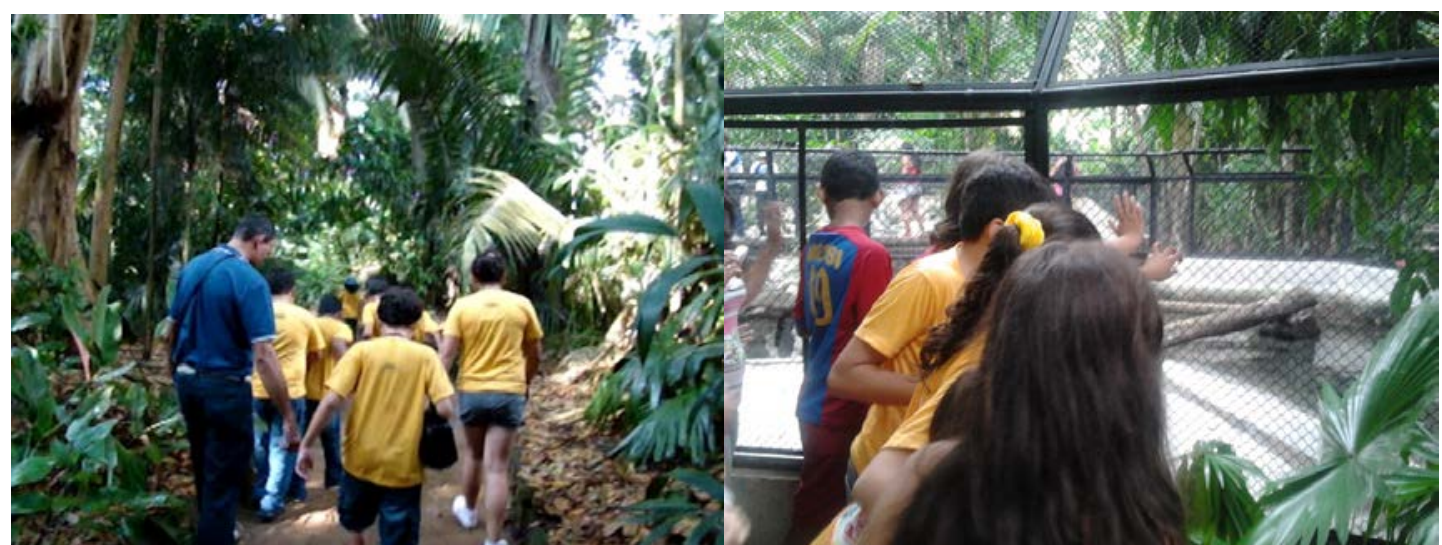

FIGURA 05 e 06 - Atividades realizadas no Parque Zoobotânico pelos pesquisadores mirins do grupo Lagartos da Amazônia. Fonte: acervo da pesquisa.

Em uma dinâmica dos grupos focais, pedimos que eles apontassem uma palavra que viesse à cabeça deles quando falássemos Museu Goeldi. As palavras citadas são apresentadas na FIGURA 07.

\begin{tabular}{|c|c|c|c|c|c|}
\hline \multicolumn{2}{|c|}{ Grupo 1} & \multicolumn{2}{|c|}{ Grupo 2} & \multicolumn{2}{|c|}{ Grupo 3} \\
\hline Palavras & $\begin{array}{c}N^{\circ} \text { de } \\
\text { ocorrências }\end{array}$ & Palavras & $\begin{array}{c}\mathrm{N}^{\circ} \text { de } \\
\text { ocorrências }\end{array}$ & Palavras & $\begin{array}{c}\mathrm{N}^{\circ} \text { de } \\
\text { ocorrências }\end{array}$ \\
\hline Animais & 6 & Conhecimento & 1 & Animais & 2 \\
\hline Bichos & 1 & Aprendizado & 1 & Animais e árvores & 1 \\
\hline Ariranha & 1 & Sustentabilidade & 1 & Plantas & 1 \\
\hline História & 1 & Encontro & 1 & Natureza & 1 \\
\hline \multirow[t]{4}{*}{ Amazônia } & 1 & Animais & 1 & Biodiversidade & 1 \\
\hline & & Fauna e Flora & 1 & Pesquisador & 1 \\
\hline & & Amazônia & 1 & Pesquisa & 1 \\
\hline & & & & Antigo & 1 \\
\hline
\end{tabular}

FIGURA 07 - Palavras citadas sobre o Museu Goeldi na dinâmica das palavras-chave nos grupos focais. 
Entre os pesquisadores mirins mais novos tanto em idade quanto em tempo de participação no Clube, percebemos a associação imediata feita por eles entre o Museu Goeldi e aquilo que veem no Parque Zoobotânico, especialmente os animais. Esse destaque dos animais em parte se deve à proximidade dos pesquisadores à fauna do Parque, já que algumas espécies ficam livres. A intimidade dos menores com os animais também é promovida porque muitos deles recebem nomes de pessoas, como a cutia Paulo Henrique, a ariranha Laila, o jacaré Alcindo e a iguana ${ }^{5} \mathrm{Korol}^{6}$.

Mesmo entre o grupo dos veteranos, que relaciona mais o Museu a uma ideia mais ampla de instituição de pesquisa, há quem mencione aspectos mais empíricos do que o ambiente do Parque lhes disponibiliza, já que muitas vezes tem a oportunidade de acompanhar o tratamento dos animais pelos técnicos que cuidam da fauna do Parque.

Eu acho muito interessante a forma que eles tratam os animais aqui, porque é uma visão que o pessoal ainda não tem. Passa, vê os animais tudo lá na jaula, mas não vê o trabalho que as pessoas têm de alimentar, cuidar. Quando eles ficam doentes vão lá tratar no local que eles têm aqui no Museu (GRUPO FOCAL 2, 2012).

Em parte essa apropriação pode ser explicada pelo caráter lúdico das atividades desenvolvidas no Parque, assim como acontece de maneira mais pontual na maioria dos museus interativos. Da mesma forma, a dimensão lúdica dos games, citada por Jianmim (2005-2006), já faz parte do cotidiano do Clube desde a sua concepção e hoje é uma das suas características mais fortes. Todos os grupos, ao final do seu processo de pesquisa e descobertas, têm que produzir algum material explicativo ou expositivo sobre o que construíram em termos de conhecimento ao longo do ano. Tradicionalmente, o formato escolhido pela maioria das turmas é o jogo, além de cartilhas e kits educativos.

Esses materiais são pensados coletivamente em cada grupo e sempre que possível, em alguns anos com mais recursos e em outros com menos, os jogos são construídos e dinamizados no dia do encerramento das atividades anuais quando é feita uma grande apresentação das turmas no Parque com a presença de familiares e do público frequentador do Museu.

\footnotetext{
${ }^{5}$ Espécime de lagarto muito encontrado em regiões tropicais.

${ }^{6}$ A iguana foi encontrada no Parque e recolhida pelo grupo Lagartos da Amazônia para observação ao longo do ano. Eles criaram um viveiro para o réptil e cuidam dele regularmente. O nome é uma homenagem à instrutora auxiliar do grupo, porém usado no masculino, apesar de o sexo do animal não ter sido identificado.
} 
É a forma com que a gente vai disponibilizar essa informação que a gente buscou. A gente está com essa informação já, a gente já foi atrás, já colheu esses dados todos. Então a gente não pode restringir essas informações. A gente tem que fazer de uma forma ampla para que todos tenham acesso àquela informação. E a gente traz isso como produto final das crianças, que é como eles vão materializar aquilo que eles estudaram durante o ano e vão tentar socializar com as pessoas aquilo que eles estudaram (EXPESQUISADORA MIRIM 2, 2013).

Dessa forma, a proposta dos jogos acaba por ser uma forma de os pesquisadores mirins comunicarem de forma lúdica as experiências e os conhecimentos que construíram: “Quando eles apresentam o produto para o público, seria a divulgação de um produto que eles construíram a partir do entendimento de ciência que eles têm. Talvez isso seja divulgação da ciência” (INSTRUTORA 3, 2013).

Jianmin (2005-2006) destaca como terceira característica do fenômeno da popularização da ciência a crescente qualificação profissional na área. No Brasil, registramos a criação de associações e cursos de graduação e pós-graduação que têm buscado atender ao interesse por essa temática de pesquisa, seja na área da Comunicação, nas Ciências da Informação ou na Museologia, sem contar com atores de outras áreas que se debruçam sobre a pesquisa e a prática da divulgação científica.

A quarta característica da popularização da ciência para o autor chinês está ligada ao envolvimento do público jovem. Trata-se do vínculo da popularização da ciência com a educação científica desde a educação básica que, como o autor exemplifica, já acontece de forma bastante interessante nos EUA, mas que, no Brasil, ainda se dá de forma bastante embrionária. Atividades diferenciadas, como as realizadas pelo Museu Goeldi, no âmbito do estado do Pará, são experimentais e requerem exploração teórica.

Por fim, o quinto ponto registrado por Jianmin (2005-2006) é a emergente demanda de que os próprios cientistas popularizem a ciência que produzem. Se olharmos o histórico da ciência e da sua divulgação a públicos externos ao campo científico, percebemos que, na prática, foram os próprios pesquisadores, nas diversas áreas, os precursores dessa atividade. Com a inserção de alguns "mediadores” no processo, como jornalistas, biblioteconomistas e museólogos (apenas para citar alguns profissionais), os cientistas se viram como que desobrigados dessa tarefa. Hoje, a tendência é exigir-se muito mais do pesquisador a atenção não apenas às suas pesquisas, mas ao compartilhamento de seus resultados, ainda que os casos sejam pontuais e expressem posturas mais individuais do que contextuais. 
No Clube, é comum o convite a pesquisadores do próprio Museu Goeldi e de outras instituições de pesquisa do estado para conversar com as crianças e adolescentes. Os instrutores apontam avanços nesse diálogo com os pesquisadores da instituição:

Tem pesquisador que tem dificuldade mesmo ou não gosta, se sente muito preso para fazer isso [dialogar com o público infanto-juvenil]. Hoje já tem alguma regra que diz que pela produção dele e tal, para ganhar promoção, eles têm que fazer essa parte mais de repassar para a comunidade mesmo. Aí já procuram a gente. Antigamente a gente procurava, a gente tinha que estar atrás do pesquisador. Hoje não, tem pesquisador: “-Olha, estou trabalhando com isso. Vocês não querem fazer uma turma no Clube do Pesquisador Mirim?”, “-Ah, está legal. Olha, ano que vem eu vou trabalhar com a senhora, trabalhar com o senhor. Pode deixar.” Então, a gente já tem isso também (INSTRUTOR 7, 2013).

Diversos são os fatores que podem levar, na atualidade, à maior disponibilidade e disposição do pesquisador em promover e participar de ações de popularização da ciência. Como mencionado pelos agentes do Clube, ainda há muita resistência em dialogar com públicos para além dos pares; em grande medida, essa atuação do pesquisador se dá como uma obrigação diante da pressão de agências de fomento; mas também há quem se apaixone e se envolva com essas atividades.

Por fim, trazemos o conceito de cultura científica, que Vogt (2006) utiliza para abranger e complementar as diversas noções que denominam a divulgação científica e a inserção da ciência na vida cotidiana.

Melhor do que alfabetização científica (tradução para scientific literacy), popularização/vulgarização da ciência (tradução para popularization/vulgarization of science), percepção/compreensão pública da ciência (tradução para public understanding/awarness of science), a expressão cultura científica tem a vantagem de englobar tudo isso e conter ainda, em seu campo de significações, a ideia de que o processo que envolve o desenvolvimento científico é um processo cultural, quer seja ele considerado do ponto de vista de sua produção, de sua difusão entre pares ou na dinâmica social do ensino e da educação, ou ainda, do ponto de vista de sua divulgação na sociedade, como um todo, para o estabelecimento das relações críticas necessárias entre o cidadão e os valores culturais de seu tempo e de sua história (VOGT, 2006, p. 24-5).

Vogt (2003) constrói a imagem da espiral da cultura científica para explicar como esta se constitui, quem são seus atores sociais e institucionais e que atividades eles desenvolvem. Na FIGURA 08, resumimos os quadrantes que o autor define. 
$1^{\circ}$ Quadrante
PRODUÇÃO E DIFUSÃO CIENTÍFICAS

Destinadores: cientistas.

Destinatários: cientistas.

Atores institucionais: universidades, centros de pesquisa, órgãos governamentais, agências de fomento, congressos, revistas científicas.

\section{$3^{\circ}$ Quadrante}

ENSINO PARA A CIÊNCIA

Destinadores: cientistas, professores, diretores de museus, animadores culturais da ciência.

Destinatários: estudantes e, mais amplamente, o público jovem.

Atores institucionais: museus e feiras de ciência. $2^{\circ}$ Quadrante

ENSINO E FORMAÇÃOO CIENTÍFICAS

Destinadores: cientistas e professores.

Destinatários: estudantes.

Atores institucionais: universidades, sistema de ensino fundamental e médio, sistema de pósgraduação.

\section{$4^{\circ}$ Quadrante \\ DIVULGAÇÃO CIENTÍFICA}

Destinadores: jornalistas e cientistas.

Destinatários: cidadão, sociedade organizada e em geral.

Atores institucionais: revistas de divulgação científica, páginas e editorias de jornais voltadas para o tema, programas de televisão, entre outros.

FIGURA 08 - Quadrantes que compõem a espiral da cultura científica. Fonte: VOGT, 2003.

De forma abrangente, a noção de cultura científica de Vogt (2003) agrega os conceitos de difusão científica (entre pares), formação científica (no âmbito da graduação e da pósgraduação), ensino ou educação para a ciência (no âmbito da educação básica) e divulgação científica (em que os meios de comunicação massivos são agentes significativos). O autor, assim, estabelece um movimento contínuo das relações entre o campo científico e a sociedade, em que sempre, ao se completar um ciclo, há novos conhecimentos e práticas a integrarem as vivências dessa cultura.

A espiral da cultura científica, ao cumprir o ciclo de sua evolução, retornando ao eixo de partida, não regressa, contudo, ao mesmo ponto de início, mas a um ponto alargado de conhecimento e de participação da cidadania no processo dinâmico da ciência e de suas relações com a sociedade (VOGT, 2003).

A partir desses parâmetros, poderíamos visualizar de imediato a experiência do Clube entre o segundo e o terceiro quadrantes, cujo foco está na formação para a ciência envolvendo estudantes. Porém, dependendo do ponto de vista que adotamos, é possível ainda considerar que, em proporções diferenciadas, os pesquisadores mirins e os instrutores seriam também agentes construtores e difusores de conhecimento, situados, portanto, no primeiro quadrante; 
assim como divulgadores científicos por meio das mídias que elaboram como produtos finais de suas pesquisas, como os jogos e cartilhas.

Porém, apesar de bastante interessantes e didáticas, as divisões estabelecidas por Vogt (2003) têm como pano de fundo uma ideia evolutiva e cumulativa da ciência, em que um conhecimento científico é linearmente desenvolvido sempre a partir do ponto em que o anterior foi (temporariamente) interrompido.

Além disso, o autor acaba por estratificar em níveis (quadrantes) a relação entre ciência e sociedade, revelando processos em que persiste a exclusividade de detenção do conhecimento científico aos cientistas e a alguns profissionais a quem é dada a concessão de difundir esse conhecimento, no caso, os professores e os jornalistas. A sociedade em geral não integra o quadrante da produção e só tem acesso à ciência na forma da educação e da divulgação científicas, sempre como que pela conscientização dos cientistas em relação à importância de tornar o conhecimento científico um elemento constituinte da cultura geral das pessoas.

A ideia de cultura científica ainda pressupõe a existência de uma cultura que se diferencia da cultura em geral, da qual, na prática, não deveria estar alheia, tampouco pode se dizer na que está isenta de interferir. Lévy-Leblond (2006), assim, considera que para além da difusão de uma cultura científica, pensemos no retorno mesmo da ciência à cultura, ainda que saibamos que, na prática, essa separação só se deu em nível teórico.

O que quero dizer é que hoje não mais existe uma "cultura científica”. O problema é muito mais grave do que o acarretado por uma simples busca de meios mais eficientes para a difusão de uma cultura científica, suposto apanágio dos cientistas e que precisa apenas ser transmitida ao público leigo. O problema está na (re)inserção da ciência na cultura, e isso requer uma profunda mudança do próprio modo de fazer ciência (LÉVY-LEBLOND, 2006, p. 33).

\subsection{A crítica da divulgação a partir da área da Comunicação}

Chegamos, pois, a uma questão central da discussão sobre comunicação da ciência e que só se tornou visível a partir de nossa experiência de pesquisa no ambiente do Clube do Pesquisador Mirim do Museu Goeldi. O fenômeno da comunicação da ciência envolve diferentes dimensões que tecem a relação permanente da ciência com a cultura, com a vida. Assim, por exemplo, o gosto pela ciência que um pesquisador mirim tem está, em diversas medidas, relacionado ao afeto construído entre os agentes do Clube, ou com a forma lúdica com que descobre e não apenas assimila uma informação científica, ou ainda com a 
possibilidade de sua família estar integrada e vivenciar essa experiência também. Portanto, a ciência, em comunicação, não existe pura e simples.

Porém, em todas essas noções de divulgação científica e os termos equivalentes e/ou complementares que aqui apresentamos, o que se percebe é a manutenção de um modelo hermético de transmissão de informações em que só se valoriza uma parte do processo, a emissão, pois é nela que se encontra o saber "verdadeiro". Nas discussões, o público é esquecido como heterogêneo e conhecedor de outros saberes tão importantes quanto o científico.

Esse perfil de pensamento também é conhecido em literatura inglesa como deficiency model, traduzido como modelo de déficit, que consiste na construção de uma ideia de que o público em geral está em desvantagem em termos de conhecimento por não dominar as informações básicas sobre os resultados das pesquisas científicas e o processo de construção do conhecimento científico. Não tendo o básico, essas pessoas também estariam desprovidas de uma melhor capacidade de atuação social, política e cultural (ZIMAN, 1991; LEWEINSTEIN, 2003).

As limitações dos variados conceitos que buscam entender a relação da ciência com a sociedade possivelmente tem a ver com as próprias restrições e contradições das ideias e das práticas de ciência a partir das quais os autores trabalham. Na área da Comunicação, esse investimento ainda é mais desafiador pela condição epistemológica de nossa área, em que para uns se trata de um campo intersecionado por vários campos, para outros, um conjunto de conhecimentos que busca se consolidar pela sua particularidade em relação a outros saberes entre outras posições que ficam entre as duas visões (BRAGA, 2011; FRANÇA, 2001; LOPES, 2006; MARTINO, 2007).

Tocamos nessa questão epistemológica para evidenciar que ela acaba resvalando no estado da arte das pesquisas em Comunicação que estudam as atividades de divulgação científica. Em levantamento não exaustivo e não representativo ${ }^{7}$, encontramos um estado da arte das pesquisas sobre divulgação científica no Brasil cujo foco está na análise de estratégias, principalmente a partir de referenciais midiáticos (o papel dos meios massivos como divulgadores) e linguísticos (os discursos sobre ciência nos meios massivos).

São preocupações recorrentes nessas pesquisas em Comunicação, encontrar formas de tornar o tema científico linguisticamente mais acessível e interessante. Por outro lado,

\footnotetext{
7 Tomamos por base os artigos apresentados ao Grupo de Pesquisa Comunicação, Ciência, Meio Ambiente e Sociedade, nos últimos dez anos, nos congressos nacionais da Sociedade Brasileira de Estudos Interdisciplinares da Comunicação (Intercom), um dos principais fóruns de discussão da área da Comunicação na América Latina.
} 
refletem como esses assuntos estão retratados na mídia, verificando as fontes de informação, os interesses institucionais e as qualidades das notícias geradas pela especialidade do jornalismo científico. Encontramos também outras pesquisas interessadas em espaços que não são necessariamente midiáticos, mas trabalham em grande parte com recursos comunicacionais: os museus de ciência.

Massarani (2008) destaca a importância de dois movimentos na atualidade na área da divulgação científica: conhecer as pesquisas já desenvolvidas e exercitar o vínculo teoria e prática: "Em primeiro lugar, precisamos conhecer melhor a produção prática e intelectual na área de divulgação científica no país, bem como produzir uma ponte sólida entre a prática e a pesquisa na área” (MASSARANI, 2008, p. 1).

Para a área da Comunicação, o exercício agrega dois empreendimentos: o primeiro, um mergulho profundo para compreender os processos comunicacionais como fenômenos humanos complexos (midiáticos ou não) e, segundo, a busca por novos referenciais comunicacionais (FRANÇA, 2001) que vislumbrem análises em nossa área para além de modelos de base funcionalista, que persistem dominantemente em muitas práticas e concepções de comunicação.

\section{CONSIDERAÇÕES}

O que podemos perceber nas noções de divulgação científica e suas variantes é que se sobressai uma visão funcionalista desses fenômenos, que, por sua vez, está ligada a concepções e práticas de produção de conhecimento científico fundamentadas em paradigmas rigidamente modernas. De forma mais ou menos explícita, alguns conceitos reproduzem características de uma ciência que se desenvolveu no advento da Modernidade e de um modelo de processo comunicacional funcionalista. Objetividade, racionalidade, rigidez metódica e criticidade; repasse de informações, público passivo e emissor isolado; em menor ou maior grau, essas noções estão presentes nas diferentes concepções e denominações dos fenômenos que envolvem a relação entre a ciência e a sociedade.

O processo de produção de conhecimento contemporâneo, porém, para além de atividades de difusão dos resultados de pesquisa, tem exigido a incorporação de estratégias comunicacionais como prática essencial e integrada da ciência.

Falar de comunicação em lugar de divulgação enfatiza uma relação que representa a condição prévia para que se possa considerar o tema dos 
conteúdos científicos, mais ou menos densos. A tendência recorrente a reduzir o tema da comunicação da ciência a mera transferência de conhecimento não apenas é uma ilusão, mas frequentemente produz o contrário da intenção inicial: aproximar, compartilhar e estimular. A comunicação da ciência não pode se furtar a uma reflexão estratégica com o falaz pretexto de que inclui a palavra mágica "ciência”! (VOGT, 2006, p. 22-3).

Nossa proposição se encaminha, assim, para pensar a inerência da comunicação à ciência, estando a esta integrada não apenas como uma prestação de contas, ou uma disponibilização final dos resultados das pesquisas ou ainda uma atividade assessória dos pesquisadores, mas como a base para o diálogo contemporâneo da ciência com os diversos âmbitos sociais, o diálogo do conhecimento científico com outras formas de conhecimento, como o senso comum.

Assim, no lugar da recorrente discussão da divulgação científica, propomos pensar em uma comunicação da ciência, em que o conhecimento científico e o senso comum se relacionam, tensionam, constroem outros conhecimentos, em um processo colaborativo de produção - e não transmissão - de conhecimento científico, que envolve também diversificados contextos sociais. Esta é, pois, a compreensão de ciência de Santos (1989, p. 13), como "prática social de conhecimento, uma tarefa que se vai cumprindo em diálogo com o mundo e que é afinal fundada nas vicissitudes, nas opressões e nas lutas que o compõem e a nós, acomodados ou revoltados”.

Para isso, um investimento fundamental é refletir sobre o conceito de comunicação. No geral, porém, o que percebemos é que a prática e a reflexão da divulgação científica privilegiam a dimensão técnica da comunicação, seja do ponto de vista da linguagem como ferramenta de tradução, seja da concepção das mídias como meras difusoras, transmissoras de informações científicas. O problema da divulgação científica e suas variantes (alfabetização, educação, popularização, percepção pública, entre outras) reside, pois, na abordagem informacional, técnica e unidirecional com que historicamente elas vem sendo encaradas e desenvolvidas.

Acredito que o objetivo da divulgação científica não pode mais ser pensado em termos de transmissão do conhecimento científico dos especialistas para os leigos; ao contrário, seu objetivo deve ser trabalhar para que todos os membros da nossa sociedade passem a ter uma melhor compreensão, não só dos resultados da pesquisa científica. A perspectiva mais distante, ainda que neste momento possa parecer utópica, é mudar a ciência de forma que ela possa finalmente diluir-se na democracia (LÉVY-LEBLOND, 2006, p. 43). 
Nesse contexto, encontramos alguns elementos para se pensar em uma comunicação da ciência, concepção que não busca substituir os demais conceitos e práticas, mas apontar aspectos que estão na base desses processos - ou poderiam estar - em diversas proporções, a fim de que as fronteiras entre ciência e sociedade diluam-se e que consigamos perceber a ciência integrada em nossa cultura.

A ideia de comunicação da ciência, mais do que a crítica às práticas historicamente desenvolvidas, deve enfatizar o que há de comunicacional nas diversas formas de manifestação e rótulos das relações entre ciência e sociedade, a partir da compreensão de que “a ciência não existe sem comunicação. Essa característica a distingue de todas as atividades exercidas na sociedade. Mais que isso, a ciência é fundamentalmente comunicação” (ROLAND, 2006, p. 62). Essa empreitada, porém, não cabe mais neste artigo e ficará para um próximo.

\section{REFERÊNCIAS}

ALVIM, Paulo César R. Comunicação da ciência. In: DUARTE, Jorge; BARROS, Antônio Teixeira de. Comunicação para ciência, ciência para comunicação. Brasília: Embrapa Informação Tecnológica, 2003.

BRAGA, José Luiz. Constituição do campo da Comunicação. Verso e Reverso. São Leopoldo: n. 25. 2011b. p. 62-77. jan./abr. 2011b.

BUENO, Wilson da Costa. Jornalismo científico no Brasil: os compromissos de uma prática dependente. 1984. Tese apresentada à Escola de Comunicação e Artes da Universidade de São Paulo. São Paulo: ECA/USP, 1984.

CAPOZOLI, Ulisses. A divulgação e o pulo do gato. In: MASSARANI, Luisa Medeiros; MOREIRA, Ildeu de Castro; BRITO, Fátima. Ciência e público: caminhos da divulgação científica no Brasil. Rio de Janeiro: Casa da Ciência - Centro Cultural de Ciência e Tecnologia da Universidade Federal do Rio de Janeiro. Fórum de Ciência e Cultura, 2002, p. 121-131.

CHASSOT, Attico. Alfabetização Científica: uma possibilidade para a inclusão social. Revista Brasileira de Educação, n. 22, p. 89-100, jan.-abr. 2003.

DURANT, John. What is scientific literacy. European Review, v. 2, jan. 1994, p. 83-9.

FRANÇA, Vera Veiga. Paradigmas da comunicação: Conhecer o quê? Trabalho apresentado no X Encontro da Compós, Brasília, 2001. Disponível em:

<www.compos.org.br>. Acesso em: 28 nov. 2010, 14 h25.

JIANMIN, Li. Estudio sobre la popularización de la ciencia en las ciudades modernas.

Quarck, n. 37-38, p. 72-82, set. 2005-abr. 2006. 
LÉVY-LEBLOND, Jean-Marc. Cultura científica, impossível e necessária. In: VOGT, Carlos (Org.). Cultura Científica: desafios. São Paulo: FAPESP, 2006. p. 28-43.

\section{LEWENSTEIN, Bruce V. Models of public communication of science and technology,} 2003. Disponível em:

http://www.somedicyt.org.mx/assets/hemerobiblioteca/articulos/Lewenstein_Models_of_com munication.pdf. Acesso em: 04/02/2013, 01:29.

LOPES, Maria I. V. de. O campo da comunicação sua constituição, desafios e dilemas.

Revista Famecos. Porto Alegre, n.30, ago. 2006, p. 16-30. Disponível em:

$<$ http://www.revistas.univerciencia.org/index.php/famecos/article/view/487/411>. Acesso em: 21 nov. 2010, 01h55.

MALDONADO, Alberto Efendy G. A perspectiva transmetodológica na conjuntura de mudança civilizadora em inícios do século XXI. In: MALDONADO, Alberto Efendy G.; BONIN, Jiani Adriana; ROSÁRIO, Nísia Martins do (Orgs.). Perspectivas metodológicas em comunicação: desafios na prática investigativa. João Pessoa: Editora Universitária da UFPB, 2008. p. 27-54.

MARTINO, Luiz Claudio (Org.). Teorias da comunicação: muitas ou poucas? Cotia: Ateliê Editorial, 2007.

MASSARANI, Luisa Medeiros. Divulgação científica: considerações sobre o presente momento, ComCiência, 2008. Disponível em:

$<$ http://www.comciencia.br/comciencia/handler.php?section=8\&edicao=37\&id=440>. Acesso em 03 mar. 2013.

MASSARANI, Luisa Medeiros; MOREIRA, Ildeu de Castro. A retórica e a ciência: dos artigos originais à divulgação científica. Multiciência: a linguagem da ciência. v. 4. mai. 2005. p. 1-18.

ROLAND, Marie-Claude. Convite aos pesquisadores para uma reflexão sobre suas práticas de pesquisa. In: VOGT, Carlos (Org.). Cultura Científica: desafios. São Paulo: FAPESP, 2006. p. 56-82.

SÁNCHEZ MORA, Ana Maria. A divulgação da ciência como literatura. Rio de Janeiro: Casa da Ciência - Centro Cultural de Ciência e Tecnologia da Universidade Federal do Rio de Janeiro: Editora UFRJ, 2003.

SANTOS, Boaventura de Sousa. Introdução a uma ciência pós-moderna. Rio de Janeiro: Graal, 1989.

VOGT, Carlos (Org.). Cultura Científica: desafios. São Paulo: FAPESP, 2006.

VOGT, Carlos. A espiral da cultura científica. São Paulo: FAPESP, 2003.

WOLF, Mauro. Teorias da Comunicação. 4. ed. Lisboa: Editorial Presença, 1995.

ZAMBONI, Lilian Márcia Simões. Cientistas, jornalistas e a divulgação científica: subjetividade e heterogeneidade no discurso da divulgação científica. Campinas: Autores Associados, 2001.

ZIMAN, John. Public Understand of Science. Science, Technology and Human Values, v. 16, p. 99-105, 1991. 
Original recebido em: 30/04/2013

Aceito para a publicação em: 20/07/2013

Maria A. Malcher

Doutora e Mestre em Ciências da Comunicação pela Universidade de São Paulo (USP). Coordenadora do Programa de Pós-Graduação Comunicação, Cultura e Amazônia (PPGCOM) e Professora da Faculdade de Comunicação Social (FACOM), Universidade Federal do Pará (UFPA). Coordenadora do Laboratório de Pesquisa e Experimentação em Multimídia da Assessoria de Educação a Distância da UFPA e do Projeto Academia Amazônia, produtora audiovisual da UFPA.

\section{Luciana M. Costa}

Pós-doutoramento em 2013, em Comunicação na Universidade Nova de Lisboa. Doutora em Ciências: Desenvolvimento Socioambiental pelo NAEA/UFPA (2004), com estágio de doutoramento na Universidade de Indiana (Anthropological Center for Training and

Research on Global Environmental Change) e no Woods Hole Research Center, ambos nos Estados Unidos da América. Mestre em Planejamento do Desenvolvimento pela Universidade Federal do Pará (1996). É professora do Programa de Pós-Graduação Comunicação Cultura e Amazônia e da Faculdade de Comunicação da UFPA.

Suzana C. Lopes

Mestrado em andamento em Ciências da Comunicação pelo Programa de Pós-Graduação Comunicação, Cultura y Amazônia da Universidade Federal do Pará (UFPA). Bolsista da Coordenação de Aperfeiçoamento de Pessoal de Nível Superior. Graduada em Comunicação Social - Habilitação em Jornalismo (UFPA). 